\title{
Unexpected One-Pot Synthesis of Highly Conjugated Pentacyclic Diquinoid Compounds
}

\author{
Alessia Coletti, $^{\dagger}$ Sara Lentini, ${ }^{\dagger}$ Valeria Conte, ${ }^{\dagger}$ Barbara Floris, $^{\dagger}$ Olga Bortolini, ${ }^{\ddagger}$ Fabio Sforza, ${ }^{\S}$ \\ Fabrizia Grepioni," and Pierluca Galloni*, ${ }^{\dagger}$ \\ ${ }^{\dagger}$ Dipartimento di Scienze e Tecnologie Chimiche, Università di Roma “Tor Vergata”, Via della Ricerca Scientifica snc, 00133 Roma, \\ Italy \\ ${ }^{\ddagger}$ Dipartimento di Chimica, Università di Ferrara, Via Luigi Borsari 46, 44100, Ferrara, Italy \\ ${ }^{\S}$ Dipartimento di Biochimica e Biologia Molecolare, Università di Ferrara, Via Fossato di Mortara 74, 44121 Ferrara, Italy \\ "Dipartimento di Chimica “Giacomo Ciamician”, Università di Bologna, Via Selmi 2, 40126, Bologna, Italy
}

Supporting Information

ABSTRACT: A new class of pentacyclic diquinoid compounds has been synthesized with a facile one-pot reaction of two molecules of 2-hydroxynaphthoquinone and 1-bromoalkanes in the presence of ferrocene. These molecules were isolated as enol tautomers that exhibit intramolecular hydrogen bond and extended electronic conjugation as proved by the intense absorption spectrum with a broad band between 400 and $600 \mathrm{~nm}$. The spectroscopic and electrochemical characterization of this new class of compounds has been performed. One of the synthesized diquinoid derivatives showed a significant cytotoxicity with $\mathrm{IC}_{50}$ values of $25-50 \mu \mathrm{M}$ against Cisplatin-Resistant SKOV3 and colon carcinoma SW480 cell lines. The results of our study provide a valuable tool to a one-pot synthesis of highly conjugated polyquinones, analogous to important biological systems, with significant antitumoral activity.

\section{INTRODUCTION}

Naphthoquinone-based molecules are ubiquitous in plants, having key roles in several transformations. ${ }^{1}$ Vitamin $\mathrm{K}$ derivatives, for example, are naphthoquinones involved in biological processes such as the catalysis of the cyclic photophosphorylation pathways ${ }^{2}$ and the decarboxylation of glutamic acid. ${ }^{3}$ Moreover, in the photosynthetic system, quinones act as the final electron acceptors in reaction centers after sunlight harvesting process. The understanding of the photosynthetic mechanism has stimulated the synthesis of artificial mimicking models, based on electron transfer processes. Accordingly, the donor and acceptor moieties used in such models are mainly inspired by the pigments found in photosynthetic reaction centers. ${ }^{4}$ Therefore, quinones have often been used as acceptor moieties together with easily oxidizable compounds, such as porphyrin or ferrocene derivatives, in donor-acceptor dyads mimicking natural photosynthesis. $^{5}$

In this paper we described a new and unexpected synthesis of highly coniugated pentacyclic diquinoid compounds. Although our initial aim was not the diquinones formation, we studied these products because of their interesting absorption properties and in view of their relevance in many fields, and in particular in medical applications. ${ }^{6}$
For example, a quinoid tricyclic derivative with antibiotic properties, the hipposudoric acid (Chart 1a), was isolated from the skin secretion of hippopotamus after a sequence of extraction processes. ${ }^{7}$ The chemical synthesis of hypposudoric acid is possible, but only with a difficult, time-consuming multistep route, ${ }^{7 \mathrm{~b}}$ as usually occurs for the synthesis of natural poliquinonoid compounds. ${ }^{8}$ Due to its absorption spectrum in the visible region, hipposudoric acid appears to be produced to

Chart 1. Diquinoid Compounds in Nature ${ }^{a}$<smiles>O=C(O)Cc1cc(=O)c2c(C(=O)O)c3c(=O)ccc(O)c-3c=2c1=O</smiles>

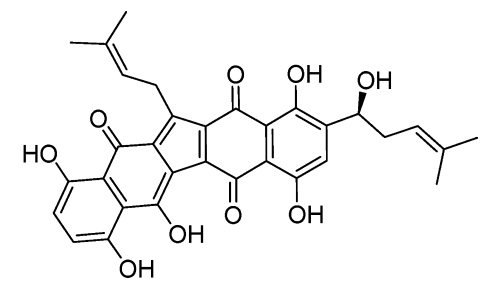

b a (a) Structure of hipposudoric acid. (b) Structure of one of the shikonin derivatives after microbial transformation.

Received: May 23, 2012

Published: July 26, 2012 
act as a sunscreen for the skin of the hippopotamus. A similar compound, with potential antitumoral, antibacterial and antiinflammatory properties, was isolated after microbial transformation of the red naphthoquinone pigment shikonin (Chart 1b). ${ }^{9}$ For this last molecule, to the best of our knowledge, a synthetic approach has not yet been developed. Additionally, one of the most fascinating capacity of quinones and poliquinones, it is to exhibit, in several cases, antitumor properties. $^{10}$

\section{RESULTS AND DISCUSSION}

The electron transfer processes that occur in ferrocenecontaining systems have been one of our interests for a number of years. ${ }^{11}$ In that respect, the synthesis and investigation of covalently linked ferrocene-naphtoquinones dyads was undertaken and initially the reference compound, 2butoxynaphthoquinone, was synthesized from 2-hydroxynaphthoquinone and 1-bromobutane, using $\mathrm{K}_{2} \mathrm{CO}_{3}$ in DMSO at 60 ${ }^{\circ} \mathrm{C}$ for $24 \mathrm{~h}$; yields improved, using an excess of 2hydroxynaphthoquinone, up to $40 \%$ with respect to the published value. ${ }^{12}$ Subsequently, we tried to obtain, by the same $S_{N} 2$-type reaction, a ferrocene containing 2-hydroxynaphthoquinone derivative using 11-bromoundecylferrocene. Interestingly, the main product of the reaction, together with unreacted 2-hydroxynaphthoquinone, was a purple powder containing a ferrocene unit, with a spectroscopic behavior incoherent with the expected $\mathrm{S}_{\mathrm{N}} 2$ product. This product, obtained in $4 \%$ yield, has been identified; however, complete spectroscopic characterization is currently under investigation. To understand the origin of such product, we then performed the reaction with 1-bromobutane and ferrocene in place of 11bromoundecylferrocene. Also under these conditions a purple product was obtained, with spectroscopic features similar to those of the ferrocene-containing molecule. Crystals of this second compound were obtained by slow evaporation of a dichloromethane solution. X-ray diffraction (Figure 1) revealed,

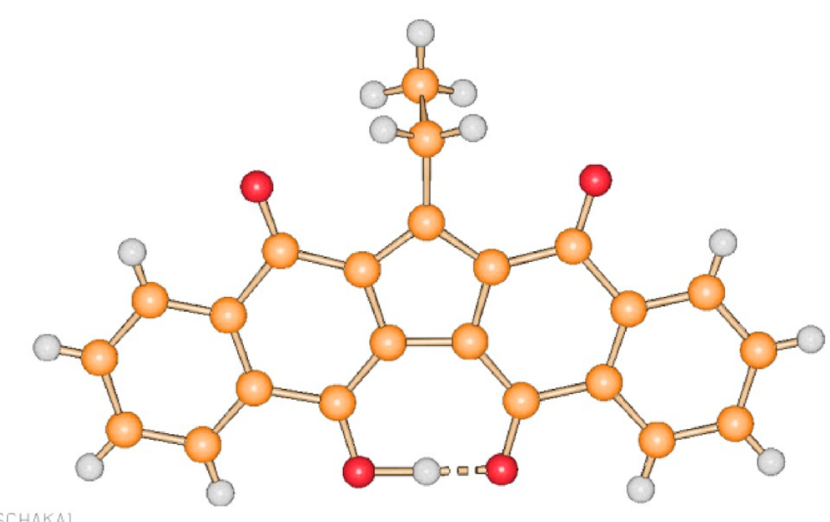

Figure 1. Molecular structure of compound 1-ethyl-KuQuinone, showing the short intramolecular $\mathrm{O}-\mathrm{H} \cdots \mathrm{O}$ hydrogen bond $[\mathrm{O} \cdots \mathrm{O}$ 2.499(3) ̊].

beyond any doubt, the formation of a pentacyclic diquinoid structure, originated from two 2-hydroxynaphthoquinone molecules and butyl bromide, surprisingly with the absence of one carbon atom in the alkyl chain. The compound has been fully characterized by ESI-MS, elemental analysis, HR-MS, IR, ${ }^{1} \mathrm{H}$ NMR, ${ }^{13} \mathrm{C}$ NMR, UV-vis, HPLC, fluorescence spectros- copy and cyclic voltammetry (see Experimental Section) and all the results are consistent with the reported structure.

Synthesis of KuQuinones. The pentacyclic diquinoid system obtained can be considered a naphthoquinone derivative. As the IUPAC name of this compound is complex, further complicated by the presence of the enol group, we decided to call it with the trivial name of KuQuinone (KuQ), in similarity to vitamin $\mathrm{K}$. Since it is possible to obtain KuQuinones bearing different alkyl chains on the five membered ring, we start to number the positions of the pentacyclic system from the differently substituted carbon atom, as shown in Figure 2. The pentacyclic compound having an ethyl chain is therefore 1-ethylKuQuinone (1-EtKuQ).

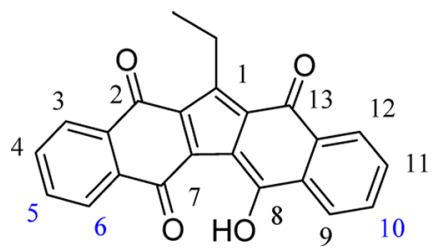

Figure 2. Structure of 1-ethylKuQuinone, showing the numbering of the pentacyclic system.

Concerning the reaction, 1-ethylKuQuinone was obtained from two molecules of 2-hydroxynaphthoquinone and one of 1bromobutane, with the loss of two hydroxyl groups (Scheme 1).

\section{Scheme 1. Synthesis of 1-EthylKuQuinone from 2- Hydroxynaphthoquinone and 1-Bromobutane ${ }^{a}$}

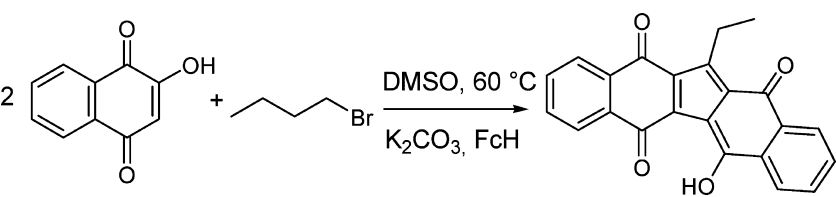

${ }^{a} \mathrm{FcH}=$ Ferrocene.

The inserted alkyl chain, involved in the formation of the central five membered ring, is one carbon atom shorter. Three carbonyl functions were retained in the product, one being present in its enol form stabilized by hydrogen bond with the nearest carbonyl group. This provides extended conjugation throughout the molecule. X-ray diffraction studies clearly show the hydroxyl hydrogen in between the two oxygen atoms, as it can be seen in Figure 1 .

The presence in solution of the enol group is supported by the very high value of the chemical shift, $18 \mathrm{ppm}$, of the hydrogen atom in the ${ }^{1} \mathrm{H}$ NMR spectrum. This tautomer is responsible for the strong acidity of the involved hydrogen atom, as already reported in the literature for similar structures (see Chart 1a). ${ }^{7 c}$ Such chemical behavior is strongly influenced by the solvent properties, suggesting the possibility of using KuQuinone derivatives in solvent polarity studies.

Several efforts were made to understand the mechanism of this reaction and to explore the applicability of this method to other halides. In particular, the reaction conditions for the synthesis of the reference compound (1-EtKuQ) were varied, to elucidate the role of solvent, base, halogen, and catalyst. The results reported in Table 1 allow us to draw some general features of the reaction. 
Table 1. Reaction Conditions Screening for the Synthesis of 1-EthylKuQuinone ${ }^{a}$

\begin{tabular}{cclllc} 
entry & $\mathrm{RCH}_{2} \mathrm{X}$ & solvent & \multicolumn{1}{c}{ base } & catalyst & yield $(\%)^{b}$ \\
1 & $\mathrm{BuBr}$ & $\mathrm{DMSO}$ & $\mathrm{K}_{2} \mathrm{CO}_{3}$ & $\mathrm{FcH}$ & 1 \\
2 & $\mathrm{BuCl}$ & $\mathrm{DMSO}$ & $\mathrm{K}_{2} \mathrm{CO}_{3}$ & $\mathrm{FcH}$ & 0 \\
3 & $\mathrm{BuI}$ & $\mathrm{DMSO}$ & $\mathrm{K}_{2} \mathrm{CO}_{3}$ & $\mathrm{FcH}$ & 0 \\
4 & $\mathrm{BuBr}$ & $\mathrm{DMSO}$ & $\mathrm{Na}_{2} \mathrm{CO}_{3}$ & $\mathrm{FcH}$ & traces \\
5 & $\mathrm{BuBr}$ & $\mathrm{DMSO}$ & $\mathrm{Cs}_{2} \mathrm{CO}_{3}$ & $\mathrm{FcH}$ & 1 \\
6 & $\mathrm{BuBr}$ & $\mathrm{DMF}$ & $\mathrm{K}_{2} \mathrm{CO}_{3}$ & $\mathrm{FcH}$ & 0 \\
7 & $\mathrm{BuBr}$ & Acetone & $\mathrm{K}_{2} \mathrm{CO}_{3}$ & $\mathrm{FcH}$ & 0 \\
8 & $\mathrm{BuBr}$ & DMSO & & $\mathrm{FcH}$ & 0 \\
9 & $\mathrm{BuBr}$ & DMSO & $\mathrm{K}_{2} \mathrm{CO}_{3}$ & & $\sim 1^{d}$ \\
10 & $\mathrm{BuBr}$ & DMSO & $\mathrm{K}_{2} \mathrm{CO}_{3}$ & $\mathrm{Cp}_{2} \mathrm{Co}$ & $\sim 1$ \\
11 & $\mathrm{BuBr}$ & DMSO & $\mathrm{K}_{2} \mathrm{CO}_{3}$ & $\mathrm{Me}_{10} \mathrm{Fc}$ & $\sim 1$ \\
12 & $\mathrm{BuBr}$ & DMSO & $\mathrm{K}_{2} \mathrm{CO}_{3}$ & $\mathrm{FeSO}_{4}$ & $<1$ \\
13 & $\mathrm{BuBr}$ & DMSO & $\mathrm{K}_{2} \mathrm{CO}_{3}$ & $\mathrm{KO}_{2}$ & 1
\end{tabular}

${ }^{a}$ Solvent $6 \mathrm{~mL}$, 2-hydroxynaphthoquinone $0.47 \mathrm{M} ; \mathrm{RCH}_{2} \mathrm{X} 0.14 \mathrm{M}$; base $0.6 \mathrm{M}$; Cat. $0.12 \mathrm{M} ; 24 \mathrm{~h}, 60{ }^{\circ} \mathrm{C}$. ${ }^{b}$ Reported yields are after column chromatography purification and repeated crystallizations. ${ }^{c}$ Reflux. ${ }^{d}$ Reaction time one week.

DMSO appears to play an important role in the outcome of the reaction, since the purple product does not form in other solvents (see entries 6 and 7). To note, the reaction does not occur in the absence of a base (entry 8 ); furthermore its nature is important: in fact, by using $\mathrm{Na}_{2} \mathrm{CO}_{3}$, instead of $\mathrm{K}_{2} \mathrm{CO}_{3}$, the $\mathrm{S}_{\mathrm{N}} 2$ reaction becomes predominant. Also the role of the halogen atom is central: bromoalkanes being reactive, while chloro- and iodoalkanes are not (entries 1-3). The reaction occurs also in the absence of ferrocene (entry 9), but it is very slow, and at the same temperature, the yield of 1 -EtKuQ becomes comparable only after one week. Likely ferrocene acts as a catalyst and its redox properties play a key role. Using metal complexes with lower reduction potentials, such as cobaltocene and decamethylferrocene, yields did not increase significantly (entries 10 and 11).

Based on all this experimental evidence, an hypothesis about the reactive route of the process has been developed (Scheme 2 ). One of the most noticeable features is that each reagent plays a role in the reaction; the peculiarity of the DMSO compared to other similar aprotic solvents such as DMF, is due to the instantaneous formation of long-lived radicals in the presence of small amounts of bases. ${ }^{13}$ This radical formation is assumed to occur through an initial fast proton abstraction from DMSO by the base, forming $\mathrm{DMSO}^{-}$anion, which loses a single electron resulting in DMSO. As reported in several previous studies with electron spin resonance, the radical species generated in these conditions easily react with the oxygen present in the solvent, producing the stable superoxide radical anion $\mathrm{O}_{2}^{-\cdot} \cdot{ }^{14,15}$ Ferrocene may catalyze the formation of the latter oxidizing species which subsequently can react with bromoalkanes to give the corresponding alkylperoxy radical. ${ }^{16}$ The most surprising feature of KuQ formation is the loss of one carbon atom, apparently from the bromoalkane chain. A reasonable explanation is a process known in literature as Hooker reaction that is typical of 2-hydroxynaphthoquinones in basic and oxidant conditions. ${ }^{17}$ Alkylperoxide species can be involved in the oxidative step of Hooker reaction, where the oxidation of a 2-hydroxy-3-alkylnaphthoquinone causes the ring-opening; successively, one carbon atom is lost from the opened ring through a decarboxylation process and the alkyl chain is implicated in the ring closure. A reaction using $\mathrm{KO}_{2}{ }^{16}$
Scheme 2. Tentative Mechanistic Pathway for the Formation of 1-RKuQuinone<smiles>[R]CC1C(=O)c2ccccc2C(=O)C1C(=O)C1C(=O)c2ccccc2C(=O)C(CC)C1=O</smiles>

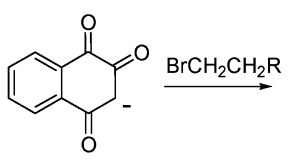<smiles>[R]CCC1C(=O)C(=O)c2ccccc2C1=O</smiles>

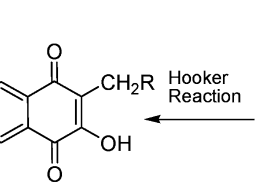<smiles>[R]CCC1C(=O)c2ccccc2C(=O)C1O</smiles><smiles>[R]C[C@H]1C(=O)c2ccccc2C(=O)[C@@]1(O)[C@H]1C(=O)c2ccccc2C(=O)[C@H]1[C@H](C)CO</smiles>

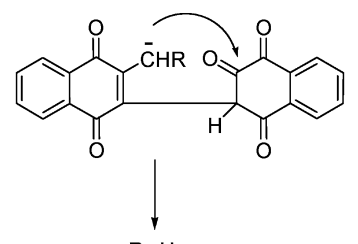<smiles>C[B-]C</smiles>
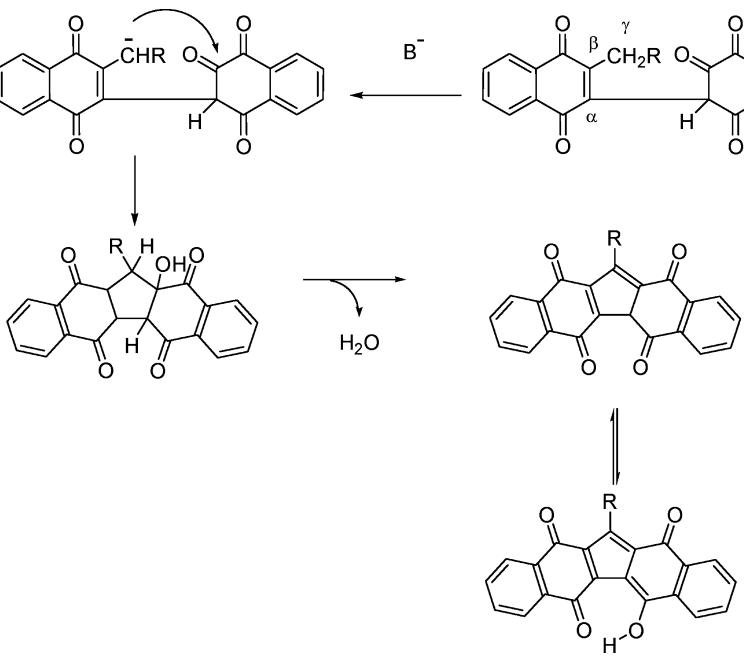

was performed to verify such hypothesis (entry 13) and comparable yield were obtained. In so far, it is difficult to isolate a possible intermediate both for the many steps of the mechanism and the overall low yield. In Scheme 2, a tentative pathway is shown: the reaction might start from carbon alkylation of the naphthoquinone. The substituted enol tautomer undergoes the Hooker rearrangement and loses one carbon atom. The dimer formation occurs through a simple sequence of aldol-type condensations and water eliminations; in particular, the deprotonation of the acidic hydrogen in $\gamma$ position could allow the pentacyclic ring closure. The final water elimination leads to the formation of the totally conjugated system. This scheme is a speculative explanation of the formation of the unexpected new polyquinoid compounds; thus, further experiments are necessary to verify our hypothesis. To note, during KuQuinones purification, other compounds were isolated in traces, and their characterization is currently undergoing.

In view of these preliminary results, several attempts were made to improve the yield of the reaction. As shown in the proposed mechanism, one of the most difficult steps could be the carbon alkylation of 2-hydroxynaphthoquinone; as a matter of fact, unreacted 2-hydroxynaphthoquinone was recovered in large amount.

Therefore, it appears that in addition to the nature of the base, the temperature, the reaction time, also the concentration and ratio of reagents influence the outcome of the process. 
Optimization of reaction conditions lead to a $13 \%$ yield for the synthesis of 1-EtKuQ (Table 2, entry 1). On the basis of such

Table 2. Optimized Reaction Conditions for the Synthesis of 1-RKuQuinone ${ }^{a}$

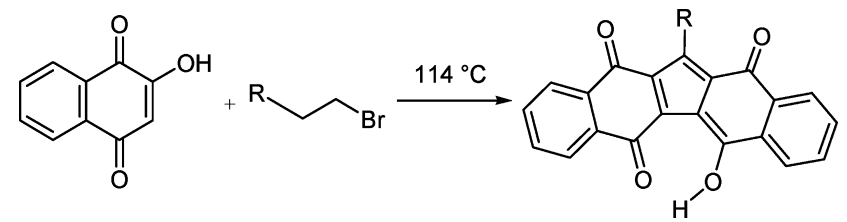

\begin{tabular}{clcccc} 
entry & \multicolumn{1}{c}{$\mathrm{RCH}_{2} \mathrm{X}$} & solvent & base & cat. & yield $(\%)^{b}$ \\
1 & $\mathrm{BuBr}$ & DMSO & $\mathrm{Cs}_{2} \mathrm{CO}_{3}$ & $\mathrm{FcH}$ & 13 \\
2 & $\mathrm{OctylBr}$ & $\mathrm{DMSO}$ & $\mathrm{Cs}_{2} \mathrm{CO}_{3}$ & $\mathrm{FcH}$ & 6 \\
3 & $\mathrm{MeBr}$ & $\mathrm{DMSO}$ & $\mathrm{Cs}_{2} \mathrm{CO}_{3}$ & $\mathrm{FcH}$ & 6 \\
4 & $\mathrm{HO}\left(\mathrm{CH}_{2}\right)_{11} \mathrm{Br}$ & DMSO & $\mathrm{Cs}_{2} \mathrm{CO}_{3}$ & $\mathrm{FcH}$ & 7,5
\end{tabular}

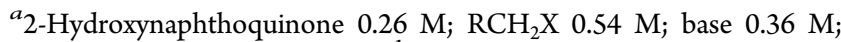
Cat. $1,5 \times 10^{-2} \mathrm{M} ; 41 \mathrm{~h} .{ }^{b}$ Reported yields are after column chromatography purification and repeated crystallizations.

result, other KuQ derivatives were synthesized by varying the length of the alkyl chain and introducing an hydroxyl function. The results are summarized in Table 2 and confirm the general scope of the reaction.

Although the yields are not very high, they are acceptable considering that the new polyquinoid compounds were obtained in a one-pot reaction and show unique features compared to analogous monoquinoid molecules. The reference compound (1-EtKuQ) has been fully characterized, spectroscopically and electrochemically, as reported in the following section.

UV-Vis and Fluorescence Properties of 1-EthylKuQuinone. The absorption and emission spectra of 1$\mathrm{EtKuQ}$ in dichloromethane are shown in Figure 3. Two intense and broad absorption bands between 500 and $600 \mathrm{~nm}$, with an $\varepsilon$ of about ten thousand, are peculiar in the UV-vis absorption spectrum of 1-EtKuQ. The internal hydrogen bond between the enol and carbonyl functions provides a planar configuration and an extended conjugation throughout the entire pentacyclic system, as it was also confirmed by theoretical DFT calculations (see Supporting Information). Upon excitation at $520 \mathrm{~nm}$ of a $2.2 \times 10^{-6} \mathrm{M}$ solution of 1-EtKuQ in dichloromethane, a fluorescence emission band has been detected at $590 \mathrm{~nm}$, as shown in Figure 3. The interesting properties of KuQuinones were evidenced by comparison of their UV-vis spectra with that of 2-butoxynaphthoquinone: in particular, significant red shift, higher $\varepsilon$ values and broader absorption range are observed (see Supporting Information, Figure S19).

Electrochemical Properties of 1-EthylKuQuinone. The redox behavior of 1-EtKuQ has been investigated in $\mathrm{CH}_{2} \mathrm{Cl}_{2} /$ TBAP by cyclic voltammetry (see Figure 4 ). The scan at

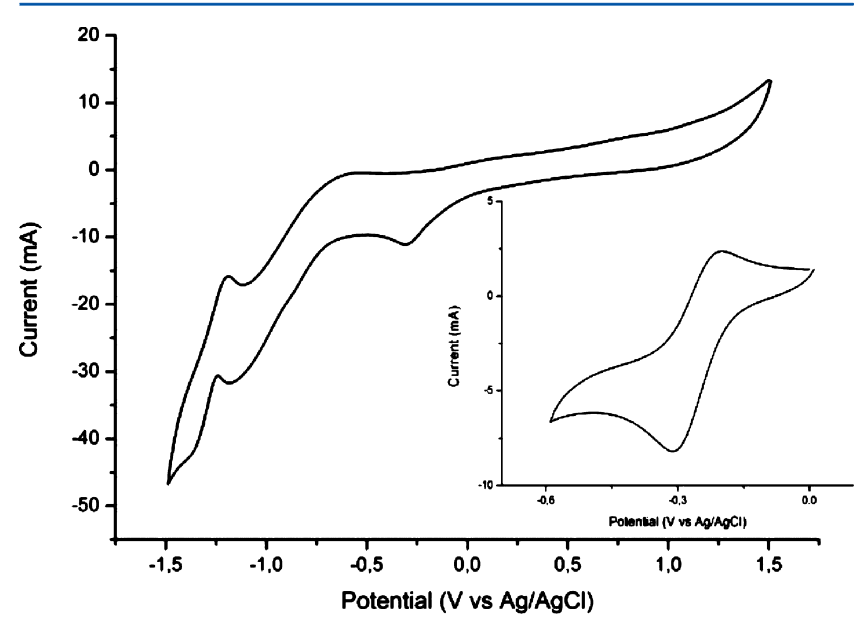

Figure 4. Cyclic voltammetry of 1-EtKuQ in $\mathrm{CH}_{2} \mathrm{Cl}_{2} 0.1 \mathrm{M}$ TBAP vs $\mathrm{Ag} / \mathrm{AgCl}$. The scan rate was $100 \mathrm{mV} / \mathrm{s}$. Inset: Cyclic voltammetry of the first reduction process occurring at $-0.26 \mathrm{~V}$.

positive potentials shows no peak, while three main peaks are present at negative voltage. The first reduction process appears at $-0.3 \mathrm{~V}$ vs $\mathrm{Ag} / \mathrm{AgCl}$ and can be reasonably assigned to the formation of a radical monoanionic species $1-\mathrm{EtKuQ}^{-}$. This process appears to be irreversible since no peak is present at similar potentials when the solution is subsequently scanned from -1.5 to $0 \mathrm{~V}$. The second process is reversible and it is present at $-1.2 \mathrm{~V}$ as a broad peak, probably due to two sequential reduction processes characterized by similar reduction potential values. The third process is present at around $-1.3 \mathrm{~V}$ but it is not well-defined because of the solvent interference, while the corresponding peak in the reverse sweep was registered at $-1.2 \mathrm{~V}$. These latter processes can be avoided by scanning the solution from 0 to $-0.6 \mathrm{~V}$, so that only the first reduction process takes place.

Under these experimental conditions, the formation of the 1$\mathrm{EtKuQ}^{-\cdot}$ species becomes a reversible process, as shown in the

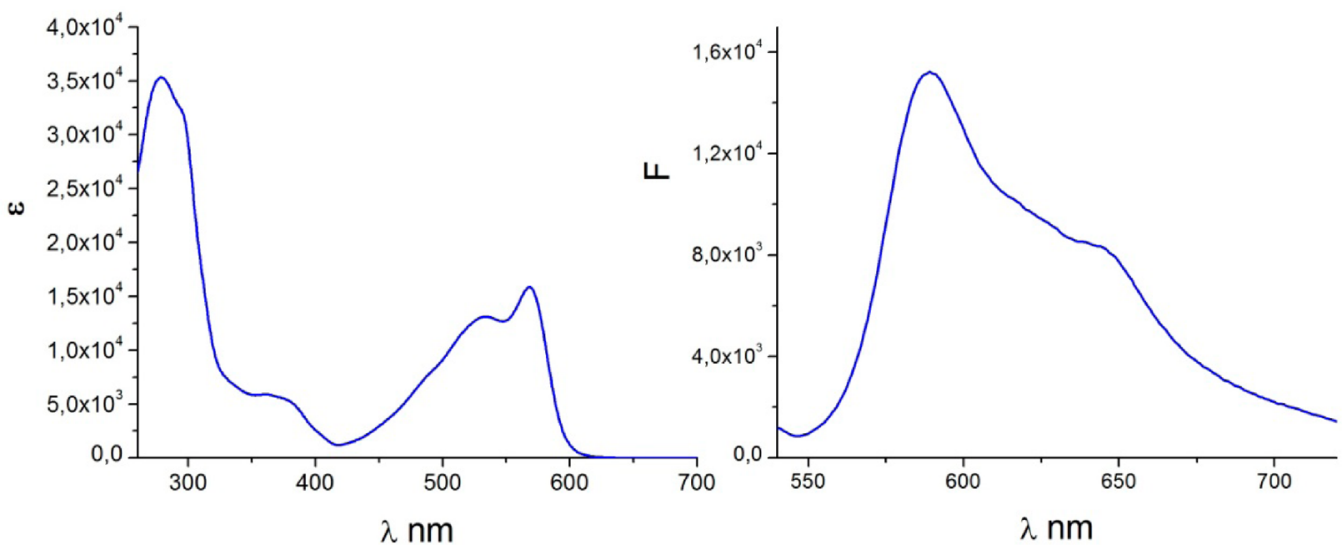

Figure 3. Absorption (left) and emission (right) spectra of 1-ethylKuQ $\left(2.2 \times 10^{-6} \mathrm{M}\right)$ in $\mathrm{CH}_{2} \mathrm{Cl}_{2}$. 
inset of Figure 4, as a new peak appears in the cyclic voltammogram. The reduction potential for the formation of the radical anion is very low if compared with the first reduction potential of vitamin $\mathrm{K}_{1}$, ${ }^{18}$ which can be considered the corresponding monoquinoid species for 1-EtKuQ. A similar observation can be made with bis-Coenzyme $\mathrm{Q}_{0}$, a diquinoid compound with interesting electrochemical and antioxidant properties ${ }^{19}$ (Table 3 ). This fact suggests that electron acceptor properties improve going from naphthoquinone derivatives to the pentacyclic diquinoid system.

Table 3. Comparison of First Reduction Potential of 1EtKuQ Vitamin $K_{1}, 2$-Butoxynaphthoquinone and the BisCoenzyme $Q_{0}$

(-EthylKuQuinone

${ }^{a}$ Value reported vs $\mathrm{FcH}$ and corrected vs $\mathrm{Ag} / \mathrm{AgCl}$.

Bioactivity of 1-EthylKuQuinone. Quinones derivatives show interesting biological activities, such as skin protection ${ }^{7}$ or anti-inflammatory, antibacterial ${ }^{9}$ and antioxidant ${ }^{19}$ properties. Moreover the most attractive application is their use as antitumor drugs. ${ }^{10}$ Therefore, we tested 1-EtKuQ for its cytotoxicity against model human solid cancer cell lines SKOV3 (Figure 5) and SW480 (Figure 6), established for ovarian and colon pathologies, respectively. Cisplatin was employed as a control. The antiproliferative activity of 1 -EtKuQ was tested with a neutral red uptake assay that provides a quantitative estimation of the number of viable cells in a culture. It is based on the ability of viable cells to incorporate and bind the

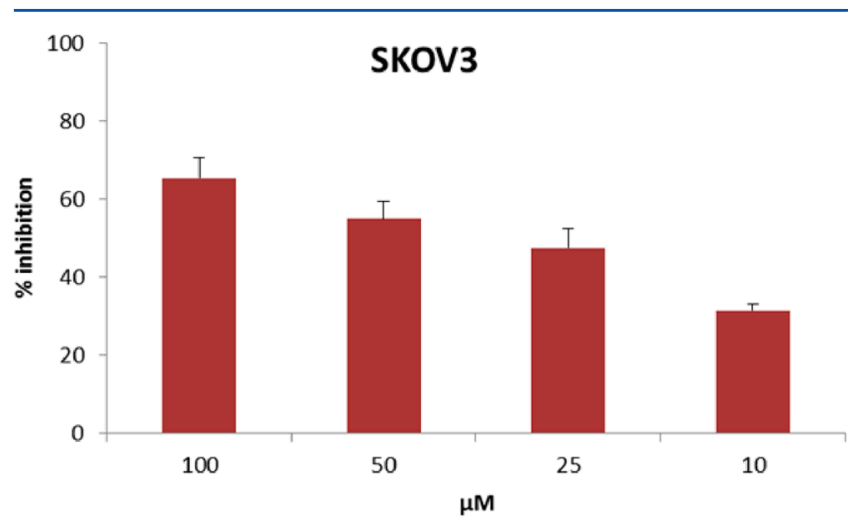

Figure 5. Antiproliferative activity of 1-EtKuQ against CisplatinResistant SKOV3 cell line after $72 \mathrm{~h}$.

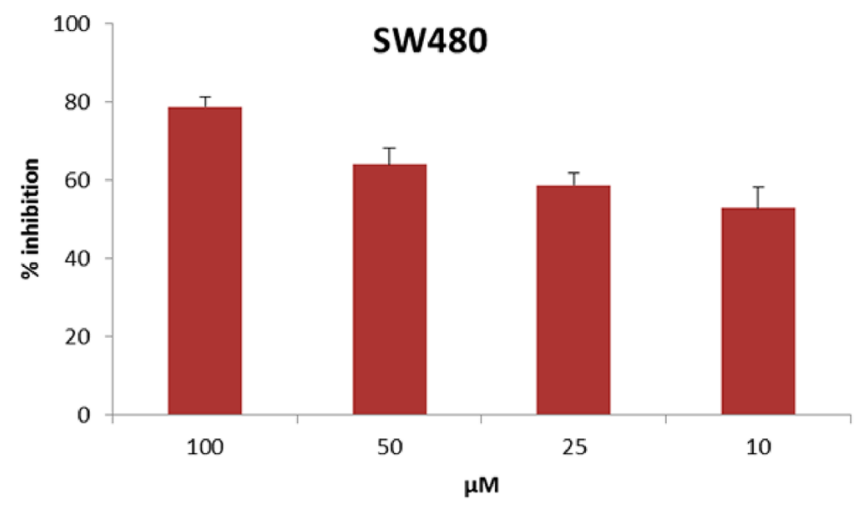

Figure 6. Antiproliferative activity of 1-EtKuQ against SW480 cell line after $72 \mathrm{~h}$.

supravital dye neutral red in the lysosomes (see Experimental section for details).

The results revealed that the molecule shows a significant growth inhibition with an $\mathrm{IC}_{50}$ value of $25-50 \mu \mathrm{M}$, which is comparable or even better than the one obtained for cisplatin on both cancer lines. More important is the negligible cytotoxic activity observed on human fibroblast, as confirmed by the high $\mathrm{IC}_{50}$ values $(>500 \mu \mathrm{M})$ shown in Figure 7. An extension of the biological activity within the NCI 60 panel of human cancers is currently in progress. ${ }^{20}$

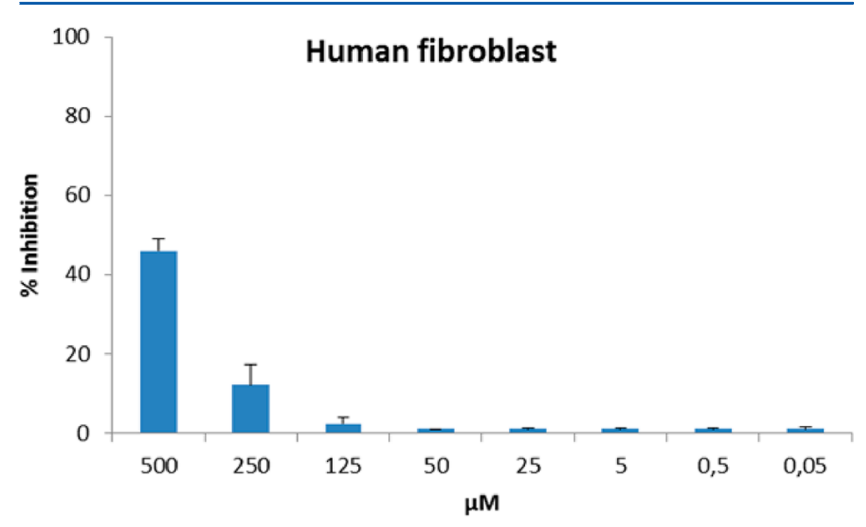

Figure 7. Cytotoxic activity of 1-EtKuQ on healthy human fibro-blasts.

\section{CONCLUSIONS}

The fairly easy access to a new class of pentacylic diquinoid compounds, KuQuinones, has been realized in a one pot reaction in acceptable yield. It must be appreciated that, with the procedure reported here, a brand new pentacyclic highly conjugated compound is obtained in a single reaction, starting from reasonably cheap materials. Preliminary investigation of the reaction mechanism has been performed, and so far, some hypotheses have been proposed to explain the formation of the cyclic molecules. Spectroscopic and electrochemical behavior of 1-ethylKuQuinone has been described. Finally, of high importance, is the observation that promising results were obtained using 1-ethylKuQ as antitumoral agent with Neutral Red Test on SKOV3 and SW480 line cells, that gave $\mathrm{IC}_{50}$ values better than that of cisplatinum and a negligible toxicity in the healthy fibroblast cells. Work is in progress to fully understand the mechanism of the reaction and the keto-enol equilibrium, to analyze redox properties in different solvents, and to further test biological activities. 


\section{EXPERIMENTAL DETAILS}

Instrumentation. The purity of each compound was checked both by elemental analysis and HPLC using a UV-vis detector, equipped with a C18 $250 \times 4.6 \mathrm{~mm}$ column and $\mathrm{MeOH} /$ water = 9:1 as eluent; all of the compounds were $\geq 99 \%$ pure. Different mass spectrometry experiments were performed on 1-EtKuQ. High Resolution Mass Spectrometry was used to confirm the structure of all the synthesized compounds (see Supporting Information for details). The solvent used to perform the UV-vis and emission fluorescence spectra was HPLC purity grade. IR spectra were carried out using $\mathrm{KBr}$ disk. NMR spectra were recorded in saturated $\mathrm{CDCl}_{3}$ solutions with a spectrometer operating at $300.13 \mathrm{MHz}$ for ${ }^{1} \mathrm{H}$ and at $100.62 \mathrm{MHz}$ for ${ }^{13} \mathrm{C}$. The NMR peak assignments are confirmed by DQF-COSY at 600.013 $\mathrm{MHz}$. Cyclic voltammetry was conducted in a $0.1 \mathrm{M}$ solution of tetrabutylammonium perchlorate (TBAP crystallized from EtOH) in anhydrous purity grade dichloromethane and was recorded from -1.5 to $1.5 \mathrm{~V}$, as shown in Figure 4, at a scan rate of $100 \mathrm{mV} / \mathrm{s}$ using a $\mathrm{Ag} /$ $\mathrm{AgCl}, \mathrm{Pt}$ disk and $\mathrm{Pt}$ wire as reference, working and counter electrodes. Single-crystal data for compound 1-EtKuQ were collected and the experimental details are given in the Supporting Information. Fully geometry optimization and orbital calculations were performed using SPARTAN ' 10 Wave function, Inc., Irvine, CA. at B3LYP 6-31 G* basis set level of theory.

Biological Activity. SKOV3 and SW480 cells were maintained in RPMI 1640, supplemented with $10 \%$ newborn bovine serum, penicillin $(100 \mathrm{U} / \mathrm{mL})$, streptomycin $(100 \mathrm{U} / \mathrm{mL})$ and glutamine $(2$ $\mathrm{mM}$ ); human fibroblasts were maintained in DMEM, supplemented with $10 \%$ newborn bovine serum, penicillin $(100 \mathrm{U} / \mathrm{mL})$, streptomycin $(100 \mathrm{U} / \mathrm{mL})$ and glutamine $(2 \mathrm{mM})$; the $\mathrm{pH}$ of the medium was 7.2 and incubation was at $37{ }^{\circ} \mathrm{C}$ in a $5 \% \mathrm{CO}_{2}$ atmosphere. Cells were routinely passaged every three days. The antiproliferative activity of $1-\mathrm{EtKuQ}$ was tested with neutral red uptake assay. ${ }^{21}$ The cells were seeded in triplicate in a 96-well plate at a density of $25 \times 10^{3}$ in $100 \mathrm{~mL}$ of RPMI $+5 \%$ FCS medium for SKOV3 and SW480, and $5 \times 10^{3}$ in $100 \mathrm{~mL}$ of DMEM $+5 \%$ FCS medium for human fibroblast. Treatment medium was removed from the 96-well plates after $72 \mathrm{~h}$, the cells were rinsed with phosphate buffered saline (PBS), $250 \mu \mathrm{L}$ NR dye medium was added to the wells $(25 \mu \mathrm{g} \mathrm{NR} / \mathrm{mL}$ concentration), and the plates were incubated (37 \pm 1 ${ }^{\circ} \mathrm{C}, 90 \pm 5 \%$ humidity, and $5.0 \pm 1 \% \mathrm{CO}_{2} /$ air) for three hours. After incubation, the NR medium was removed, the cells were rinsed with PBS, and $150 \mu \mathrm{L}$ of a desorbed solution (50\% bidistilled water, $49 \%$ ethanol, $1 \%$ acetic acid) was applied. The plates were shaken on a microtiter plate shaker for $20-45$ min to extract NR from the cells and form a homogeneous solution. The absorption (i.e., OD measurement) of the resulting colored solution was measured (within $60 \mathrm{~min}$ of adding the desorb solution) at $540 \mathrm{~nm}$ in a spectrophotometric microtiter plate reader.

Synthesis. Reagents were purchased and used without further purification. Spectrophotometric grade DMSO was kept over anhydrous $\mathrm{K}_{2} \mathrm{CO}_{3}$ overnight prior to use. Glassware was dried under $\mathrm{N}_{2}$. In a typical optimized experiment, $12 \mathrm{mmol}$ of alkyl bromide was added to $2.5 \mathrm{~g}$ (8 mmol) of anhydrous $\mathrm{Cs}_{2} \mathrm{CO}_{3}, 1 \mathrm{~g}(5.75 \mathrm{mmol})$ of 2hydroxy-1,4-naphthoquinone and $62 \mathrm{mg}(0.33 \mathrm{mmol})$ of sublimated ferrocene in $22 \mathrm{~mL}$ of DMSO. The mixture was kept under stirring at $114{ }^{\circ} \mathrm{C}$ in a dry atmosphere for $41 \mathrm{~h}$, then diluted with $100 \mathrm{~mL}$ of dichloromethane and filtered. The filtrate was extracted with water (2 $\times 500 \mathrm{~mL}$ ), dried over $\mathrm{Na}_{2} \mathrm{SO}_{4}$ and filtered. The brown powder obtained after evaporation of the solvent under reduced pressure was subsequently purified by column chromatography $\left(\mathrm{SiO}_{2}, \mathrm{CH}_{2} \mathrm{Cl}_{2}\right.$ as eluent). The isolated purple compound was then repeatedly crystallized from dichloromethane-pentane.

1-EthylKuQuinone. Purple crystal powder $(135 \mathrm{mg}, 0.38 \mathrm{mmol}$, $13.2 \%$ yield) $\mathrm{mp} 255-257^{\circ} \mathrm{C} .{ }^{1} \mathrm{H}$ NMR: $\delta 18.18(\mathrm{~s}, 1 \mathrm{H}), \delta 8.29-8.24$ $(\mathrm{m}, 4 \mathrm{H}), \delta 7.82-7.71(\mathrm{~m}, 4 \mathrm{H}), \delta 3.45(\mathrm{q}, J=7.33,2 \mathrm{H}), \delta 1.31(\mathrm{t}, J=$ 7.33, 3H). ${ }^{13} \mathrm{C}$ NMR: $\delta 180.0,176.8(\mathrm{C}=\mathrm{O}) ; 134.7,133.9,132.0$, $131.3,130.9,126.7,126.2,124.6$ (aromatic carbons); 19.9, 12.3 (aliphatic carbons). HRMS (ESI+) $m / z:[\mathrm{M}+\mathrm{H}]^{+}$calcd. for $\mathrm{C}_{23} \mathrm{H}_{15} \mathrm{O}_{4}$ 355.0970; found 355.0958. Anal. Calcd for $\mathrm{C}_{23} \mathrm{H}_{14} \mathrm{O}_{4} \cdot 1 / 2$
$\left(\mathrm{H}_{2} \mathrm{O}\right): \mathrm{C}, 76.02 ; \mathrm{H}, 4.16$. Found: $\mathrm{C}, 75.19 ; \mathrm{H}, 4.06$. UV-vis in $\mathrm{CH}_{2} \mathrm{Cl}_{2}\left[\lambda_{\max }, \mathrm{nm}\left(\varepsilon, \mathrm{M}^{-1} \mathrm{~cm}^{-1}\right)\right]: 568$ (15700); 531 (12900); 364 (5800); 278 (35000). FT-IR (KBr) $\left(\mathrm{cm}^{-1}\right): 3464$ (broad OH), 1643, 1630, $1587(\mathrm{C}=\mathrm{O})$.

1-HexylKuQuinone. Purple powder $(72 \mathrm{mg}, 0.18 \mathrm{mmol}, 6,1 \%$ yield) $\mathrm{mp} 175-177{ }^{\circ} \mathrm{C} .{ }^{1} \mathrm{H}$ NMR: $\delta 18.17(\mathrm{~s}, 1 \mathrm{H}), \delta 8.29-8.24(\mathrm{~m}$, $4 \mathrm{H}), \delta 7.81-7.70(\mathrm{~m}, 4 \mathrm{H}), \delta 3.46(\mathrm{t}, J=8.19 \mathrm{~Hz}, 2 \mathrm{H}), \delta 1.73-1.33$ $(\mathrm{m}, 8 \mathrm{H}), \delta 0.91(\mathrm{t}, J=6,66 \mathrm{~Hz}, 3 \mathrm{H}) .{ }^{13} \mathrm{C}$ NMR: $\delta 179.8$ and 176.6 $(\mathrm{C}=\mathrm{O}) ; 134.6,133.8,131.9,131.4,130.8,126.7,126.1,124.5$ (aromatic carbons); 30.8, 28.8, 28.3, 26.6, 21.7, 13.1 (aliphatic carbons). HRMS (MALDI-TOF) $m / z:[\mathrm{M}]^{+}$calcd. for $\mathrm{C}_{27} \mathrm{H}_{22} \mathrm{O}_{4}$ 410.1518; found 410.1487. Anal. Calcd for $\mathrm{C}_{27} \mathrm{H}_{22} \mathrm{O}_{4}$ : C, 79.01; $\mathrm{H}$, 5.40. Found: $\mathrm{C}, 78.71 ; \mathrm{H}, 5.38$. UV-vis in $\mathrm{CH}_{2} \mathrm{Cl}_{2}\left[\lambda_{\max }, \mathrm{nm}(\varepsilon\right.$, $\left.\mathrm{M}^{-1} \mathrm{~cm}^{-1}\right)$ ]: 570 (14700); 531 (12000); 365 (5400); 280 (31000). FT-IR in $\mathrm{KBr}\left(\mathrm{cm}^{-1}\right): 3458$ (broad OH), 1646, 1626, $1586(\mathrm{C}=\mathrm{O})$.

1-(9-Hydroxynonyl)KuQuinone. Purple powder (101 mg, 0.22 mmol, $7.5 \%$ yield) $\mathrm{mp} 157-160{ }^{\circ} \mathrm{C} .{ }^{1} \mathrm{H}$ NMR: $\delta 18.19(\mathrm{~s}, 1 \mathrm{H})$, $\delta 8.30-8.25(\mathrm{~m}, 4 \mathrm{H}), \delta 7.83-7.72(\mathrm{~m}, 4 \mathrm{H}), \delta 3.66(\mathrm{t}, J=6.66 \mathrm{~Hz}$, $2 \mathrm{H}), \delta 3.47(\mathrm{t}, J=7.68 \mathrm{~Hz}, 2 \mathrm{H}), \delta 1.30-1.44(\mathrm{~m}, 14 \mathrm{H}) .{ }^{13} \mathrm{C}$ NMR: $\delta$ 180.0 and $176.8(\mathrm{C}=\mathrm{O})$; 135.4, 134.7, 133.9, 132.8, 132.0, 126,7, 126.2, 123.9 (aromatic carbons); 62.0, 31.7, 28.21, 28.16, 28.0, 27.2, 26.5, 24.6, 24.4 (aliphatic carbons). HRMS (ESI+) $m / z:[\mathrm{M}+\mathrm{Na}]^{+}$ calcd. for $\mathrm{C}_{30} \mathrm{H}_{28} \mathrm{O}_{5} \mathrm{Na}$ 491.1834; found 491.1810. Anal. Calcd for $\mathrm{C}_{30} \mathrm{H}_{28} \mathrm{O}_{5} \cdot 1 / 2\left(\mathrm{H}_{2} \mathrm{O}\right): \mathrm{C}, 75.45 ; \mathrm{H}, 6.12$. Found: $\mathrm{C}, 75.61 ; \mathrm{H}, 6.2$. UV-vis in $\mathrm{CH}_{2} \mathrm{Cl}_{2}\left[\lambda_{\max }, \mathrm{nm}\left(\varepsilon, \mathrm{M}^{-1} \mathrm{~cm}^{-1}\right)\right]: 571$ (20000); 537 (16615); 360 (8000); 274 (45000). FT-IR in $\mathrm{KBr}\left(\mathrm{cm}^{-1}\right): 3438$ (broad OH), 1644, 1629, $1584(\mathrm{C}=\mathrm{O})$.

1-MethylKuQuinone. Purple powder $(60 \mathrm{mg}, 0.17 \mathrm{mmol}, 6.1 \%$ yield) $\mathrm{mp}>270{ }^{\circ} \mathrm{C} .{ }^{1} \mathrm{H}$ NMR: $\delta 18.11(\mathrm{~s}, 1 \mathrm{H}), \delta 8.30-8.25(\mathrm{~m}, 4 \mathrm{H}), \delta$ 7.80-7.74 (m, 4H), $\delta 2.98(\mathrm{~s}, 3 \mathrm{H}) .{ }^{13} \mathrm{C}$ NMR: $\delta 183.9$ and 180.7 $(\mathrm{C}=\mathrm{O}) ; 138.6,137.9,135.9,135.2,134.9,130.7,130.2,128.5$ (aromatic carbons); 23.8 (aliphatic carbons). HRMS (ESI-) $\mathrm{m} / z$ : [M $-\mathrm{H}]^{-}$calcd. for $\mathrm{C}_{22} \mathrm{H}_{11} \mathrm{O}_{4}$ 339.0657; found 339.0642. Anal. Calcd for $\mathrm{C}_{22} \mathrm{H}_{12} \mathrm{O}_{4} \cdot 1 / 2\left(\mathrm{H}_{2} \mathrm{O}\right): \mathrm{C}, 75.64 ; \mathrm{H}, 3.75$. Found: $\mathrm{C}, 75.60 ; \mathrm{H}, 3.56$. UV-vis in $\mathrm{CH}_{2} \mathrm{Cl}_{2}\left[\lambda_{\max }, \mathrm{nm}\left(\varepsilon, \mathrm{M}^{-1} \mathrm{~cm}^{-1}\right)\right]: 567$ (12500); 527 (10000); 364 (5100); 278 (27000). FT-IR in $\mathrm{KBr}\left(\mathrm{cm}^{-1}\right): 3452$ (broad $\mathrm{OH}), 1647,1626,1588(\mathrm{C}=\mathrm{O})$.

\section{ASSOCIATED CONTENT}

\section{Supporting Information}

${ }^{1} \mathrm{H}$ and ${ }^{13} \mathrm{C}$ NMR spectra, CIF file, HR mass spectra and optimized DFT structure. This material is available free of charge via the Internet at http://pubs.acs.org.

\section{AUTHOR INFORMATION}

\section{Corresponding Author}

*galloni@scienze.uniroma2.it

\section{Notes}

The authors declare no competing financial interest.

\section{ACKNOWLEDGMENTS}

MIUR PRIN 2008 (project PRIN 20088NTBKR) "Electrochemical and spectroscopic studies of electron transfer processes in organic self-assembled monolayers supported on inorganic materials." is acknowledged. Thanks to Dr. Silvia Pezzola and Prof. Daniel Cicero for helpful discussion, and to Dr. Ercolina Bianchini, Servizio di Analisi Elementare del Dipartimento di Scienze Chimiche e Farmaceutiche, Università di Ferrara, for elemental analysis.

\section{DEDICATION}

In Memory of Edoardo Toppani.

\section{REFERENCES}

(1) Thomson, R. H. Pharm. World Sci. 1991, 13, 70. 
(2) Whatley, F. R.; Allen, M. B.; Arnon, D. I. Biochim. Biophys. Acta 1959, 32, 32.

(3) Nelsestuen, G. L.; Zytkovicz, T. H. J. Biol. Chem. 1974, $249,6347$.

(4) Balzani, V.; Credi, A.; Venturi, M. ChemSusChem 2008, 1, 2.

(5) See for example: (a) Jono, R.; Yamashita, K. J. Phys Chem. C 2012, 116, 1445. (b) Kang, Y. K.; Iovine, P. M.; Therien, M. J. Coord. Chem. Rev. 2011, 255, 804. (c) Gust, D.; Moore, T. A. Science 1989, 244,35 .

(6) See as an example: da Silva, E. N., Jr; Cavalcanti, B. C.; Guimarães, T. T.; Pinto, M. C. F. R.; Cabral, I. O.; Pessoa, C.; CostaLotufo, L. V.; de Moraes, M. O.; de Andrade, C. K. Z.; dos Santos, M. R.; de Simone, C. A.; Goulart, M. O. F.; Pinto, A. V. Eur. J. Med. Chem. 2011, 46, 399.

(7) (a) Saikawa, Y.; Hashimoto, K.; Nakata, M.; Yoshihara, M.; Nagai, K.; Ida, M.; Komiya, T. Nature 2004, 429, 363. (b) Saikawa, Y.; Moriya, K.; Hashimoto, K.; Nakata, M. Tetrahedron Lett. 2006, 47, 2535. (c) Hashimoto, K.; Saikawa, Y.; Nakata, M. Pure Appl. Chem. 2007, 79, 507.

(8) See as an example: Padwal, J.; Lewis, W.; Moody, C. J. Org. Biomol. Chem. 2011, 9, 3484.

(9) Meselhy, M. R.; Kadota, S.; Tsubono, K.; Hattori, M.; Namba, T. Tetrahedron 1994, 50, 3081.

(10) See for example: (a) Pérez-Sacau, E.; Diaz-Peñate, R. G.; Estévez-Braun, A.; Ravelo, A. G.; Garcia-Castellano, J. M.; Pardo, L.; Campillo, M. J. Med. Chem. 2007, 50, 696. (b) Eyong, K. O.; Kumar, P. S.; Kuete, V.; Folefoc, G. N.; Nkengfack, E. A.; Baskaran, S. Bioorg. Med. Chem. Lett. 2008, 18, 5387. (c) Kongkathip, N.; Kongkathip, B.; Siripong, P.; Sangma, C.; Luangkamin, S.; Niyomdecha, M.; Pattanapa, S.; Piyaviriyagul, S.; Kongsaeree, P. Bioorg. Med. Chem. 2003, 11, 3179.

(11) (a) Vecchi, A.; Gatto, E.; Floris, B.; Conte, V.; Venanzi, M.; Nemykin, V. N.; Galloni, P. Chem. Commun 2012, 48, 5145. (b) Nemykin, V. N.; Rohde, G. T.; Barrett, C. D.; Hadt, R. G.; Bizzarri, C.; Galloni, P.; Floris, B.; Nowik, I.; Herber, R. H.; Marrani,

A. G.; Zanoni, R,; Loim, N. M. J. Am. Chem. Soc. 2009, 131, 14969.

(c) Caporossi, F.; Floris, B.; Galloni, P.; Gatto, E.; Venanzi, M. Eur. J.

Org. Chem. 2006, 4362. (d) Floris, B.; Galloni, P.; Seraglia, R.; Tagliatesta, P. J. Organomet. Chem. 2003, 679, 202.

(12) Fukuzumi, S.; Okamoto, K.; Imahori, H. Angew. Chem., Int. Ed. 2002, 41, 620.

(13) Øpstad, C. L.; Melø, T. B.; Sliwka, H. R.; Partali, V. Tetrahedron 2009, 65, 7616.

(14) Qiao, X.; Chen, S.; Tan, L.; Zheng, H.; Ding, Y.; Ping, Z. Magn. Reson. Chem. 2001, 39, 207.

(15) (a) Sawyer, D. T.; Valentine, J. S. Acc. Chem. Res. 1981, 14, 393.

(b) Andrieux, C. P.; Hapiot, P.; Saveant, J.-M. J. Am. Chem. Soc. 1987, $109,3768$.

(16) Johnson, R. A.; Nidy, E. G. J. Org. Chem. 1975, 40, 1680.

(17) Lee, K.; Turnbull, P.; Moore, H. W. J. Org. Chem. 1995, 60, 461 and references therein.

(18) Hui, Y.; Chng, E. L. K.; Chua, L. P.-L.; Liu, W. Z.; Webster, R. D. Anal. Chem. 2010, 82, 1928.

(19) Wang, X.; Ma, W.; Ying, Y.; Liang, J.; Long, Y.-T. Chem. Asian J. 2011, 6, 1064.

(20) Shoemaker, R. H. Nat. Rev. Cancer 2006, 6, 813.

(21) Repetto, G.; del Peso, A.; Zurita, J. L. Nat. Protoc. 2008, 3, 1125. 